\title{
Closed Anaerobic Biotransformation Products of Organoarsenic Compounds in Fucus distichus
}

\author{
Abiodun A. Ojo and Amos Onasanya \\ Department of Chemical Sciences, College of Sciences, Afe Babalola University, Ekiti State, Ado-Ekiti 360211, Nigeria \\ Correspondence should be addressed to Abiodun A. Ojo; abeo39@yahoo.com
}

Received 27 April 2013; Accepted 11 June 2013

Academic Editors: N. Belzile, A. Waseem, and C. Waterlot

Copyright (C) 2013 A. A. Ojo and A. Onasanya. This is an open access article distributed under the Creative Commons Attribution License, which permits unrestricted use, distribution, and reproduction in any medium, provided the original work is properly cited.

\begin{abstract}
The closed anaerobic decomposition extracts of Fucus distichus incubated with seawater and sediment, and without sediment as control, were subjected to extractions and isolation on Sephadex LH 20 and Cellulose Thin Layer Chromatography. The decomposition extracts and isolates were analyzed by using both the Hydride Generation Gas Chromatography Atomic Absorption Spectrometry (HG-GC-AAS) and High Performance Liquid Chromatography Inductively Coupled Plasma Mass Spectrometry (HPLC-ICPMS) to identify the arsenic species in the equilibrium mixtures of the seaweed and filtrates separately. In the methanol seaweed extract, equilibrium mixture of arsenosugars (AS) AS1 and AS2 and their biotransformation products of dimethylarsinoylethanol (DMAE) and dimethylarsinic acid (DMAA) were identified. In the methanol filtrate extract of the mixture, only DMAE and DMAA were identified. However, in the control methanol filtrate extract five organoarsenic species, AS1 and AS2, one unidentified hidden organoarsenic species, DMAE and DMAA were identified in the equilibrium mixture. This result confirmed that the hidden organoarsenic species in Fucus distichus, AS1 and AS2, and an unidentified organoarsenic compounds are biotransformed to only DMAE and DMAA under an anaerobic condition. This also suggests that DMAE and DMAA are strong intermediate candidates for the generation of arsenobetaine, from arsenoribosides in the marine food webs.
\end{abstract}

\section{Introduction}

Arsenic is a very ubiquitous element in the environment [1]. Inorganic and organic arsenic compounds have extremely different toxicological effects $[1,2]$. Concerns of possible human health effects of the toxic arsenic from dietary intake have continued to stimulate research on arsenic biogeochemistry including its bioaccumulation and biotransformation in both the freshwater and marine food chains [2]. Arsenic enters the marine environment from both the natural and anthropogenic point and diffuse sources $[3,4]$.

Some of the highest concentrations of arsenic in biota are encountered in marine organisms because they have the ability to concentrate arsenic from different food sources [5]. Marine plants, particularly algae, are known to accumulate high arsenic contents $[6,7]$. As primary producers, phytoplankton and marine macroalgae accumulate inorganic arsenic and biotransform them into complex organic molecules that are either water- or lipid-soluble arsenic compounds. When fed upon by the higher trophic level, the water- and lipid-soluble organoarsenicals are further metabolized into other distinct arsenicals and/or they are likely accumulated unchanged [8-10]. In the arsenic biogeochemical cycle, the formation of organoarsenicals via biomethylation of arsenic is considered to be a detoxification process in the marine and aquatic environment $[2,10]$. One organoarsenic compound that has been found to be widely distributed in marine animals and also recently found in a marine algae extract and the red Antarctic alga Phyllophora antarctica is arsenobetaine $(\mathrm{AB})[4,11,12]$. It is probably the end product of arsenic metabolism in marine food chains [4]. Studies have shown that the organic arsenosugars are the predominant arsenicals found in marine macroalgae $[3,13]$.

Biological transformation of arsenic can either be microbially mediated and/or the organism's adaptive response to the accumulated arsenic [10]. The microbial transformations of arsenic can occur via redox transformation between arsenite and arsenate, as well as through biomethylation of 
arsenic into volatile methyl arsines [10]. In a previous study, it was suggested that a microbially mediated stage, probably occurring within sediments, was necessary for the generation of arsenobetaine from arsenoribosides [14]. When Ecklonia radiata (brown kelp) was allowed to decompose under an open anaerobic condition in the presence of sea water and beach sand, the algal arsenoribosides in Ecklonia radiata were irreversibly and completely biotransformed into dimethylarsinoyl ethanol, DMAE, $\left(\mathrm{CH}_{3}\right)_{2} \mathrm{As}(\mathrm{O}) \mathrm{CH}_{2} \mathrm{CH}_{2} \mathrm{OH}$ [15]. In a related work, when samples of the brown alga Ecklonia radiata was allowed to naturally decompose under moist conditions in tubes open to air at one end only in a time series laboratory experiments, the original arsenosugars degraded after 25 days primarily to arsenate via two major intermediates, DMAE and DMAA, in the sections without direct contact with air when analyzed for arsenic species by HPLC/ICPMS following an aqueous methanol extraction [16].

It does appear that dimethyl(5-ribosyl)arsine oxides and their anaerobic degradation products, DMAE and DMAA, are the most likely candidates as intermediates for the production of arsenobetaine from oceanic arsenate in marine food webs [16-19]. However, a previous study suggested an alternative pathway by which marine organisms can produce arsenocholine by the breakdown of arsenophosphatidyl choline by phospholipases [20]. Arsenocholine (AC), $\left(\mathrm{CH}_{3}\right)_{3} \mathrm{As}^{+} \mathrm{CH}_{2} \mathrm{CH}_{2} \mathrm{OH} \mathrm{X} \mathrm{X}^{-}(\mathrm{X}=\mathrm{Cl}, \mathrm{I})$, could then be oxidized to arsenobetaine (AC), $\left(\mathrm{CH}_{3}\right)_{3} \mathrm{As}^{+} \mathrm{CH}_{2} \mathrm{COO}^{-}[21,22]$. It thus remains to be established if $\mathrm{AB}$ is formed from arsenosugars via the DMAE and/or DMAA intermediates and passed up the food chain or if organisms at different trophic levels have the ability to synthesize arsenobetaine. The debate about the pathway for the biotransformation of arsenic in the marine environment has not been completely resolved [11].

In the current work, we have used a closed anaerobic decomposition procedure on Fucus distichus to allow for the characterization of all possible metabolites occurring during the anaerobic decomposition process. This study will contribute to a complete understanding of the anaerobic decomposition process on one hand and, on the other hand, offers possible additional insights on the conversion to and accumulation of arsenobetaine in the higher trophic levels of the marine environment. The speciation of the arsenic metabolites in the equilibrium mixture of the closed anaerobic decomposition of Fucus distichus in this study was carried out by using a semicontinuous Hydride Generation Gas Chromatography Atomic Absorption Spectrometry (HG-GCAAS) and High Performance Liquid Chromatography Inductively Coupled Plasma Mass Spectrometry (HPLC-ICPMS).

\section{Materials and Methods}

2.1. Samples Collection. Fucus distichus (715.85 g wet weight) was collected at low tide on rocks almost submerged in the early morning cold water from Point Grey Wreck Beach Vancouver and placed in a large plastic container together with 3 liters of unfiltered seawater and dark sediment ( $628 \mathrm{~g})$ obtained in the same location.
2.2. Reagents. All chemicals used from BDH, Fisher Scientific, Aldrich, Eastman Kodak, Alfa, and MCIB were classified as analytical grade and meet ACS Specifications, respectively. Aqueous stock solutions (1000 ppm of arsenic) of arsenite, arsenate, monomethylarsonic acid (MMAA), and dimethylarsinic acid (DMAA) were prepared by dissolving appropriate amounts of $\mathrm{As}_{2} \mathrm{O}_{3}(\mathrm{BDH})$, $\mathrm{Na}_{2} \mathrm{HAsO}_{4} \quad 7 \mathrm{H}_{2} \mathrm{O}$ (MCIB), $\mathrm{CH}_{3} \mathrm{AsO}(\mathrm{ONa})_{2} \quad 6 \mathrm{H}_{2} \mathrm{O}$ (Alfa), and $\left(\mathrm{CH}_{3}\right)_{2} \mathrm{AsO}(\mathrm{OH})$ (Fisher). Unless otherwise stated, standard solutions were prepared by serial dilution of these stock solutions with deionized water, and sodium borohydride (Aldrich) solutions were made fresh in deionized water. The HPLC eluant used in this work is $10 \mathrm{mM}$ tetraethylammonium hydroxide $+4 \mathrm{mM}$ Malonic acid $+0.1 \%$ Methanol (HPLC grade, Fisher) at $\mathrm{pH}$ 6.8. This was prepared in deionized distilled water. The $\mathrm{pH}$ of this HPLC eluant was adjusted by using diluted nitric acid. The solution was subsequently filtered through a $0.45 \mu \mathrm{m}$ membrane filter before use. Other solvents from commercial sources were either of analytical or HPLC grade and used after filtration through millipore $0.45 \mu \mathrm{m}$ membrane filters. All glassware and plastic ware were soaked overnight in 2\% Extran solution, a cleaning agent for thorough removal of residues, followed by rinsing with tap water and then soaking in dilute hydrochloric acid overnight. The glass and plastic containers were rinsed thoroughly using tap water first and then deionized water. Arsenic stock solution $(1000 \mathrm{mg} / \mathrm{L})$ was prepared from a synthetic sample of DMAE in deionized water.

2.3. HG-GC-AAS and HPLC-ICPMS Analytical Procedures. For the determination of methylated arsenic compounds in the seaweed and filtrates extracts, samples $(0.03-0.17 \mathrm{~g})$ placed directly into separate $40 \mathrm{~mL}$ tall glass test tubes were digested with $5 \mathrm{~mL}$ of $2 \mathrm{M}$ sodium hydroxide. A hot water bath heated to $90-95^{\circ} \mathrm{C}$ by an aluminum heating block was employed for the heating carried out for three hours. On cooling, the digests were neutralized with dilute hydrochloric acid and made up to $40 \mathrm{~mL}$ with deionized water. Arsenic determination and speciation were carried out on the digestates, which in most cases were diluted prior to analysis by the HG-GC-AAS technique [23]. The hydride generation system consists of a peristaltic pump for mixing known volumes of sample (or standard) solutions with $1 \mathrm{M}$ hydrochloric acid and $2 \%$ sodium borohydride. The arsines generated were led through a gas-liquid separator using a helium carrier gas into a moisture Teflon U-trap $(30 \mathrm{~cm}$ length $\times 0.8 \mathrm{~cm}$ i.d.) immersed in a dry ice-acetone slurry and subsequently swept into a hydride trap, a Teflon U-tube $(30 \mathrm{~cm}$ length $\times 0.4 \mathrm{~cm}$ i.d.) cooled by nitrogen $\left(-196^{\circ} \mathrm{C}\right)$. The hydride was then warmed by using a water bath $\left(70^{\circ} \mathrm{C}\right)$, and the arsines were liberated and carried onto Porapak-PS column within a Varian Vista 6000 Gas Chromatography (GC). The volatile arsines were separated on the column by using a preset temperature program and detected by passing them into an air-hydrogen flame in a quartz cuvette placed carefully in the light path of an arsenic hollow cathode lamp. Detection of the arsenic absorption was achieved by using an 810-Jarrell-Ash Atomic Absorption Spectrophotometer coupled to a Hewlett Packard 3390 A Integrator. Arsenic compounds of known 


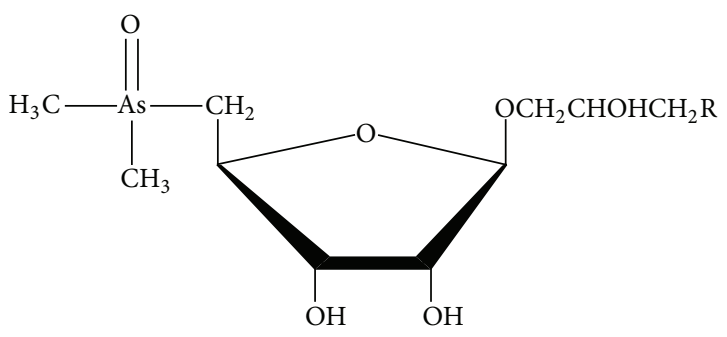

Arsenosugar 1 (AS1): $\mathrm{R}=\mathrm{OH}$

Arsenosugar 2 (AS2): $\mathrm{R}=\mathrm{OPO}_{3} \mathrm{CH}_{2} \mathrm{CHOHCH}_{2} \mathrm{OH}$

FIgURE 1: Arsenosugars found in NIST 1566a Oyster Tissue.

concentrations (10 ppb As (III), As(V), MMAA, and $20 \mathrm{ppb}$ DMAA) were used as arsenic standards and their chromatograms were compared with those of the extracts. Normal calibration procedure was used with duplicate determinations carried out on each sample (in most cases, otherwise triplicate analysis was used). The peak area absorbance mode of the AAS was normally utilized with the HG-GC-AAS technique. The experimental and instrumental operating conditions for the HPLC-ICPMS analytical procedures have been previously reported [24]. The HPLC separation (on line with the ICPMS) was carried out on an Inertsil ODS-2 (250x $4.6 \mathrm{~mm}$ id, GL Sciences, Japan) HPLC column using $10 \mathrm{mM}$ tetraethylammonium hydroxide $+4 \mathrm{mM}$ malonic acid $+0.1 \%$ methanol at $\mathrm{pH} 6.8$ as the mobile phase. The columns were equilibrated with the appropriate eluant before any sample introduction for at least two hours at $1 \mathrm{~mL} \mathrm{~min}^{-1}$. The flow rate employed was $0.8 \mathrm{~mL} \mathrm{~min}^{-1}$. The seaweed extracts and chromatographic fractions or isolates were centrifuged to remove any suspended particulates prior to ion pair chromatography on the HPLC columns. Identification of arsenic compounds present in the seaweed samples was made by matching and comparing their retention times obtained from the HPLC-ICPMS chromatograms with those of known standards using spiked and/or unspiked arsenic compounds as well as four major arsenic species, namely, AB, DMAA, AS1 and AS2 in Figure 1 found in standard reference material, NIST 1566a Oyster Tissue [9, 24].

2.4. Isolation of the Closed Anaerobic Decomposition Products. The procedure described by Edmonds et al. [15] was modified from the open to the closed condition involved incubating Fucus distichus (715.58g wet weight) at room temperature with 31 unfiltered seawater and dark sediment ( 628 g) obtained in the same location. Parafilm was used to enhance air tightness. The mixture was vigorously shaken in the dark for 11 days. A released gas, smelling obnoxiously like hydrogen sulfide, was observed during this period. After day 11 , under the continuous flow of argon, the cap was opened to release the built up gas before placing it back. Unlike in the previous open experiment where the cap was opened for the rest of the next 30 days, in this closed anaerobic condition, the cap was only opened briefly for about a minute daily and then closed back, under continuous flow of argon to remove and/or reduce the built up pressure in the equilibrium process taking place. After 41 days, the content was decanted/filtered to separate the seaweed/sediment residue from the soluble filtrate (SF). The residue (1.34 kg wet weight) was extracted (four times) in methanol to obtain a methanol extract and unextractable seaweed residue (UR). The methanol extract was evaporated to a dark brown residue $(28.58 \mathrm{~g})$ and was dissolved in deionized water to $150 \mathrm{ml}$ mark as the water soluble seaweed extract (SR).

The dark brown SF was evaporated and the filtrate residue $(89 \mathrm{~g})$ was extracted (six times) in methanol and the insoluble salty material $(52.77 \mathrm{~g})$ discarded off. The filtrate methanol extract (SF) was evaporated to a syrup which was reextracted (six times) in methanol, filtered $(125 \mathrm{ml}$ methanol soluble filtrate, SF), and the insoluble brown residue (9.44 g, IF).

Furthermore, the water soluble seaweed extract $(150 \mathrm{~mL}$, SR) was partitioned with diethyl ether $(3 \times 150 \mathrm{~mL})$ to remove insoluble fatty material and the ether layer $(0.83 \mathrm{~g})$ was discarded off. The aqueous layer was concentrated with phenol (3 times), diluted with diethylether, and the low polarity substances separated into the phenol-ether layer, whereas the highly polar materials remained in the aqueous phase. The aqueous layer was evaporated $(27.22 \mathrm{~g}$, brown residue) and reextracted several times in methanol removing methanol insoluble material $(18 \mathrm{~g})$ which was not further analyzed.

The methanol soluble seaweed extract $(125 \mathrm{~mL}, \mathrm{SR})$ was then chromatographed on Sephadex LH20 $(2.5 \mathrm{~cm} \times$ $85 \mathrm{~cm}$ ) with methanol as the mobile phase. A single arseniccontaining band which eluted between $216 \mathrm{~mL}$ and $457 \mathrm{~mL}$ was collected and then rechromatographed on the same column. Again, a single arsenic-containing band which eluted between $200 \mathrm{~mL}$ and $443 \mathrm{~mL}$ was obtained. However, two fractions were taken based on color: a leading light brown band, (SRA) between $200 \mathrm{~mL}$ and $303 \mathrm{~mL}$, and a later eluting dark brown band (SRB) between $304 \mathrm{~mL}$ and $443 \mathrm{~mL}$.

Additionally, isolates SRA and SRB were further subjected unto a cellulose thin layer chromatograph (tlc) $(200 \mathrm{~mm} \times$ $200 \mathrm{~mm} \times 0.1 \mathrm{~mm}, \mathrm{n}$-butanol: acetic acid: water, $60: 15: 25$ as the mobile phase). The isolate SRA revealed two arseniccontaining bands at Rf values 0.18-0.24 (SRA1) and 0.48-0.74 (SRA2). The isolate SRB also yielded two arsenic containing bands with Rf values of $0.18-0.21$ (SRB1) and $0.58-0.73$ (SRB2).

In a separate control experiment carried out without the beach sediment, Fucus distichus (70.40 g) in unfiltered seawater obtained from the same source was incubated under the closed anaerobic decomposition condition. After 41 days, a milky brown filtrate solution $(450 \mathrm{~mL}, \mathrm{CF})$ and a seaweed residue $(58.62 \mathrm{~g}, \mathrm{CR})$ were obtained. The seaweed residue was extracted ( 3 times) in methanol and filtered to obtain a methanol soluble seaweed extract (CR) while the remnant seaweed was discarded off. The filtrate from the control experiment was evaporated to obtain a greenish brown syrup $(15.49 \mathrm{~g})$ which was extracted in methanol (3 times), filtered and the insoluble material (7.90 g, CIF) was separated from the methanol soluble filtrate (CF, $9.23 \mathrm{~g}$ brown syrup). 
TABLE 1: Arsenic determination and speciation analysis on the decomposition products from Fucus distichus incubated in a closed anaerobic decomposition system using the semicontinuous mode HG-GC-AAS technique.

\begin{tabular}{|c|c|c|c|c|c|c|c|c|c|}
\hline \multirow{3}{*}{$\mathrm{S} / \mathrm{N}$} & \multirow{3}{*}{ Closed system anaerobic decomposition } & \multicolumn{8}{|c|}{ 3-hour hot base digestion $(2 \mathrm{M} \mathrm{NaOH}, 5 \mathrm{~mL})^{*}$} \\
\hline & & \multicolumn{4}{|c|}{ Arsenic before digestion (in $\mu \mathrm{g}$ ) } & \multicolumn{4}{|c|}{ Arsenic after digestion (in $\mu \mathrm{g}$ ) } \\
\hline & & Inorg. As & MMAA & DMAA & Total As & Inorg. As & MMAA & DMAA & Total As \\
\hline 1 & SF: Methanol filtrate extract & nd & nd & 4.72 & 4.72 & nd & nd & 8.09 & 8.09 \\
\hline 2 & IF: Insoluble filtrate material & d & $\mathrm{d}$ & 0.86 & 0.86 & d & $\mathrm{d}$ & 0.95 & 0.95 \\
\hline 3 & UR: Unextractable seaweed residue & - & - & - & - & 8.04 & 0.30 & 8.70 & 17.04 \\
\hline 4 & SRA: Early eluting methanol seaweed extract & 0.83 & 0.07 & 0.72 & 1.62 & 2.01 & 0.12 & 28.04 & 30.17 \\
\hline \multirow[t]{2}{*}{5} & SRB: Late eluting methanol Seaweed extract & 0.12 & $\mathrm{~d}$ & 0.38 & 0.50 & 2.41 & 0.67 & 24.75 & 27.83 \\
\hline & Total arsenic species & 0.95 & 0.07 & 6.68 & 7.70 & 12.46 & 1.09 & 70.53 & 84.08 \\
\hline
\end{tabular}

${ }^{*}$ Main experiment: Seaweed + Seawater + Sediment samples.

nd: not detected; d: detected; —: not determined; Inorg. As: inorganic arsenic, AsIII \& AsV; MMAA: monomethylarsonic acid; DMAA: dimethylarsinic acid.

TABLE 2: Control experiment for arsenic determination and speciation analysis on the decomposition products from Fucus distichus incubated in a closed anaerobic decomposition system using the semicontinuous mode HG-GC-AAS technique.

\begin{tabular}{llcccccccc}
\hline & & \multicolumn{4}{c}{ 3-hour hot base digestion $(2 \mathrm{M} \mathrm{NaOH}, 5 \mathrm{~mL})^{*}$} \\
S/N Closed system anaerobic decomposition & \multicolumn{3}{c}{ Arsenic before digestion (in $\mu \mathrm{g})$} & \multicolumn{3}{c}{ Arsenic after digestion (in $\mu \mathrm{g})$} \\
& & DMAA & Total As & DMAA & Total As & DMAA & Total As & DMAA & Total As \\
\hline 1 & CF: Control methanol filtrate extract & nd & nd & 0.48 & 0.48 & nd & nd & 5.13 & 5.13 \\
2 & CIF: Control methanol insoluble filtrate material & - & - & - & - & 0.70 & 0.74 & 11.68 & 13.12 \\
3 & CR: Control seaweed extract & 0.04 & nd & d & 0.04 & 0.04 & nd & 9.24 & 9.28 \\
& Total arsenic species & $\mathbf{0 . 0 4}$ & nd & $\mathbf{0 . 4 8}$ & $\mathbf{0 . 5 2}$ & $\mathbf{0 . 7 4}$ & $\mathbf{0 . 7 4}$ & $\mathbf{2 6 . 0 5}$ & $\mathbf{2 7 . 5 3}$ \\
\hline
\end{tabular}

${ }^{*}$ Control experiment: Seaweed + Seawater samples.

nd: not detected; d: detected; -: not determined; Inorg. As: inorganic arsenic, AsIII \& AsV; MMAA: monomethylarsonic acid; DMAA: dimethylarsinic acid.

\section{Results and Discussion}

The samples from the control and the main experiment were all subjected to arsenic speciation by using the combination of the three-hour hot base digestion and the semicontinuous HG-GC-AAS to determine the amount of inorganic arsenic (arsenate and arsenite), MMAA and DMAA, present before and after the digestion procedure. The arsenic speciation data obtained are shown in Tables 1 and 2.

To characterize the arsenic species, an NIST 1566a Oyster Tissue Standard Reference Material, a synthesized DMAE standard sample, and the decomposition isolates, SRA1, SRA2, SRB1, SRB2 (main experiment-seaweed/seawater/ sediment) SF, and CF (control experiment-seaweed/seawater) were analyzed and characterized by the HPLC-ICPMS technique to obtain chromatograms Figures 2-10, respectively.

The standard arsenic species (arsenobetaine, DMAA, AS1, and AS2 in the NIST 1566a Oyster Tissue standard reference material; and the DMAE synthesized standard) were analyzed and characterized by the HPLC-ICPMS technique also to give the chromatograms in Figures 2 and 3. Furthermore, the chromatogram of a combination of DMAE and DMAA isolates in Figure 4 and those of the standard arsenic species were all used for retention matching and characterization of the isolates.

The speciation analysis by using the combination of the three-hour hot base digestion with HG-GC-AAS technique revealed that majority of the arsenic species present in both

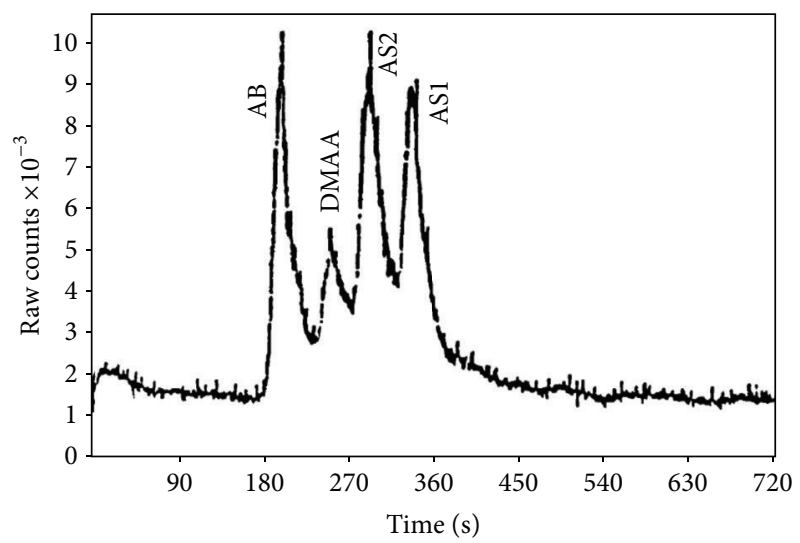

FIGURE 2: HPLC-ICPMS chromatogram obtained for NIST 1566a Oyster Tissue Standard Reference Material.

the control and the main decomposition samples were in the form of "hidden" arsenic compounds [25, 26]. Studies have shown that the majority of these hidden organoarsenic compounds in marine algae are arsenosugars [27]. Prior to the hot base digestion, the total arsenic species content for the main samples was $7.70 \mu \mathrm{g}$ As (9.15\% of the total arsenic species in the decomposition equilibrium mixture). After the hot base digestion, the total arsenic species content was $84.08 \mu \mathrm{g}$ As due to the detection of hidden organoarsenic compounds in the form of mainly dimethylated arsenic species $(70.53 \mu \mathrm{g}$ DMAA). The total arsenic contents found in the methanol 


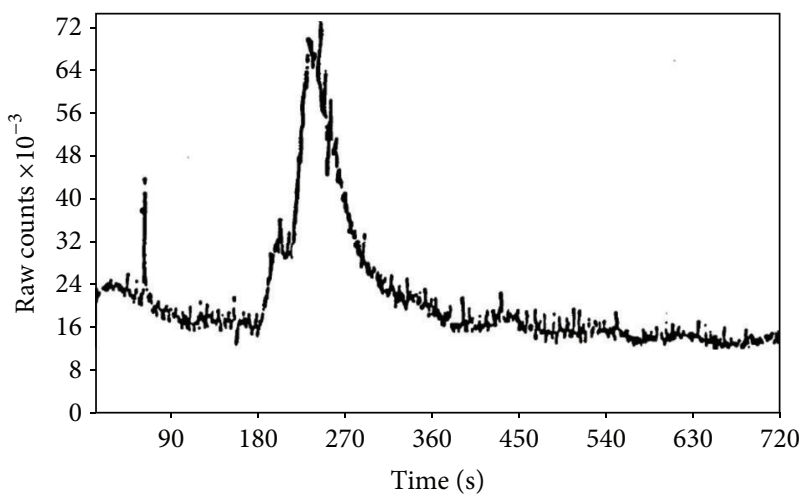

FIGURE 3: HPLC-ICPMS chromatogram obtained for DMAE.

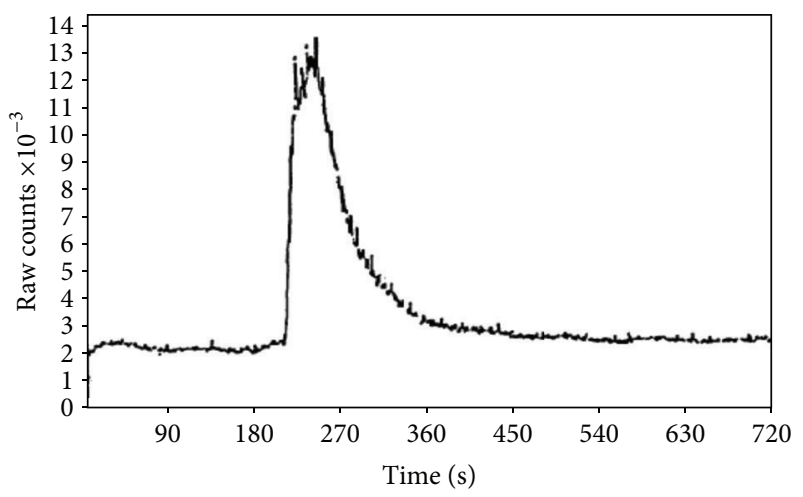

FIGURE 4: HPLC-ICPMS chromatogram obtained with a 1:3 mixture of Fucus distichus isolates of DMAE and DMAA from open anaerobic decomposition procedure.

soluble seaweed isolates SRA and SRB are, respectively, $30.17 \mu \mathrm{g}$ As and $27.83 \mu \mathrm{g}$ As representing almost $70 \%$ of the arsenic present in the Fucus distichus. It was observed that greater than $94 \%$ of the total arsenic contents in these isolates are in the forms of "hidden" arsenic species. More importantly, the biotransformation isolates samples (SRA and SRB) were found to contain a total of $1.10 \mu \mathrm{g}$ DMAA prior to the hot base digestion. This confirms that dimethylarsinic acid, DMAA, is a minor component of the closed anaerobic decomposition products of the Fucus distichus. Additionally, DMAA was also determined as minor decomposition products in both the control and main filtrate samples CF $(0.48 \mu \mathrm{g})$ and SF $(4.72 \mu \mathrm{g})$ before the hot base digestion by the HG-GC-AAS analysis. These are further confirmation to support that DMAA is a biotransformation product of the anaerobic decomposition process. It was observed that $20 \%(17.04 \mu \mathrm{g} \mathrm{As})$ of the total arsenic was unextractable after several sequential extractions with water/methanol. This unextractable arsenic has been described as recalcitrant arsenic when Ecklonia radiata was subjected to sequential extractions with water/methanol, acetone, and hexane previously [16].

The Rf values obtained for SRA1 $(0.18-0.24)$ and SRB1 (0.18-0.21), on one hand, and SRA2 (0.48-0.74) and SRB2 $(0.58-0.73)$, on the other hand, suggested that these tlc

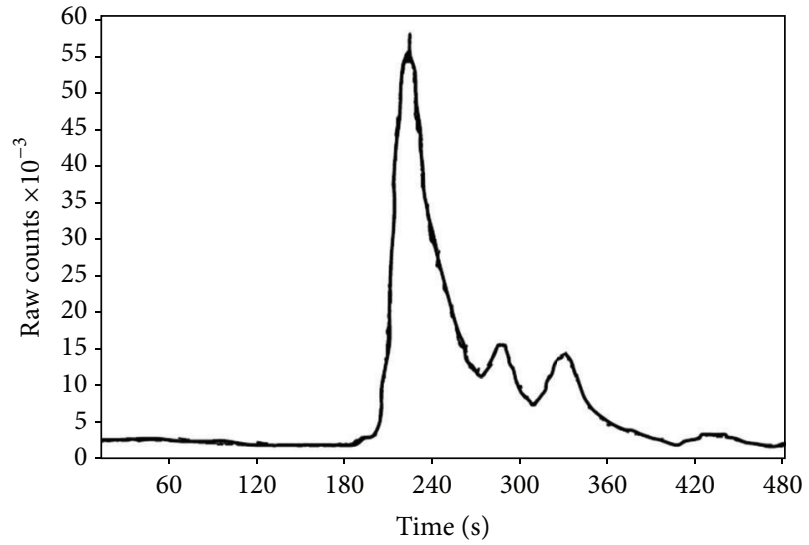

FIGURE 5: HPLC-ICPMS chromatogram obtained for SRA1 isolate.

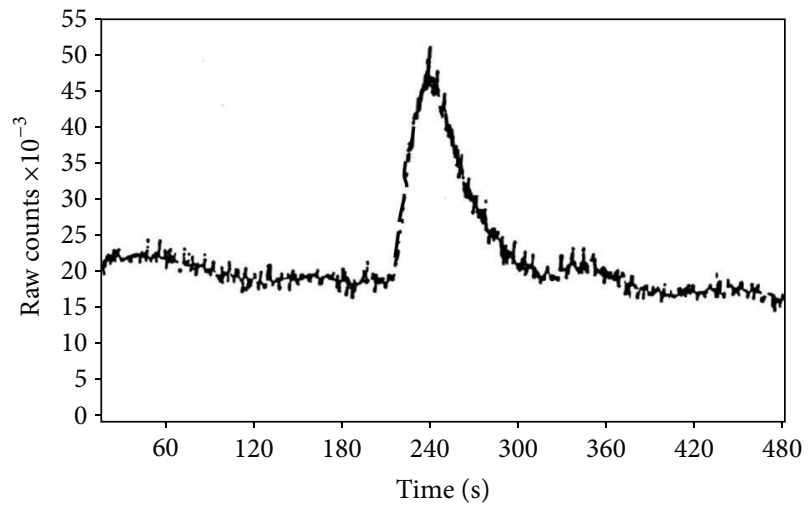

FIGURE 6: HPLC-ICPMS chromatogram obtained for SRA2 isolate.

isolates should have similar decomposition products, respectively. SRA and SRB were separated on the basis of color from a single arsenic-containing band on Sephadex LH 20 chromatographic procedure earlier on. The results of the HPLC-ICPMS chromatograms of SRA1 (Figure 5) and SRB1 (Figure 7) further confirm that these two tlc isolates are identical as they both revealed three similar arsenic peaks at retention times $194-270 \mathrm{~s}, 270-305 \mathrm{~s}$, and 305-360 s. When compared with the chromatograms of the standard samples (Figures 2, 3, and 4), the arsenic peak at 194-270 s matched the retention times for the mixture of both DMAE (major) and DMAA (minor). In addition to DMAA, DMAE is identified as one of the hidden arsenic species earlier confirmed by the HG-GC-AAS analysis. The arsenic peaks at 270-305 s and 305-360 s matched the retention times of the AS2 and AS1 (Figure 1) respectively. Arsenic peak at retention times 270-305 s and 305-360 s was identified as the AS2 and AS1, respectively. These are two separate hidden organoarsenic compounds in the Fucus distichus that have been previously identified [24]. The arsenic peak (194-275 s) of the tlc isolates SRA2 and SRB2 (Figures 6 and 8), as well as that for the filtrate sample SF (Figure 9), matched the retention times for a mixture of DMAE (major, 194-275s) and DMAA (minor, $230-275$ s). These arsenic peaks were identified as mixture of DMAE and DMAA. In a previous timed series laboratory 


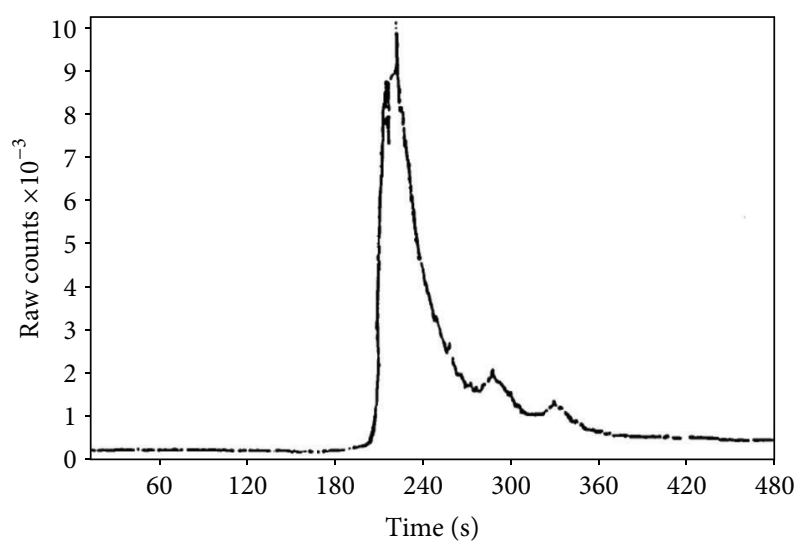

FIGURE 7: HPLC-ICPMS chromatogram obtained for SRB1 isolate.

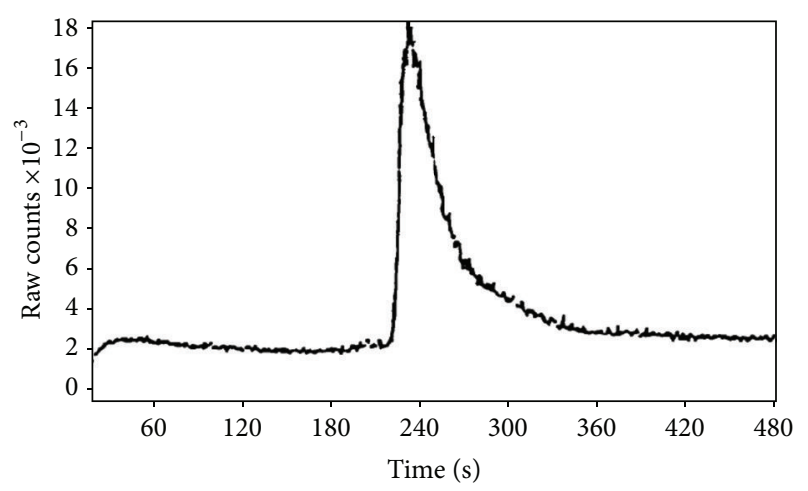

FIGURE 8: HPLC-ICPMS chromatogram obtained for SRB2 isolate.

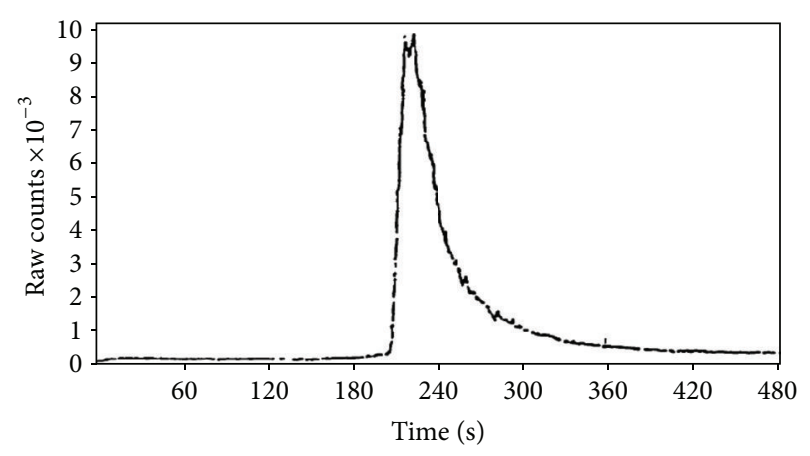

FIGURE 9: HPLC-ICPMS chromatogram obtained for SF sample.

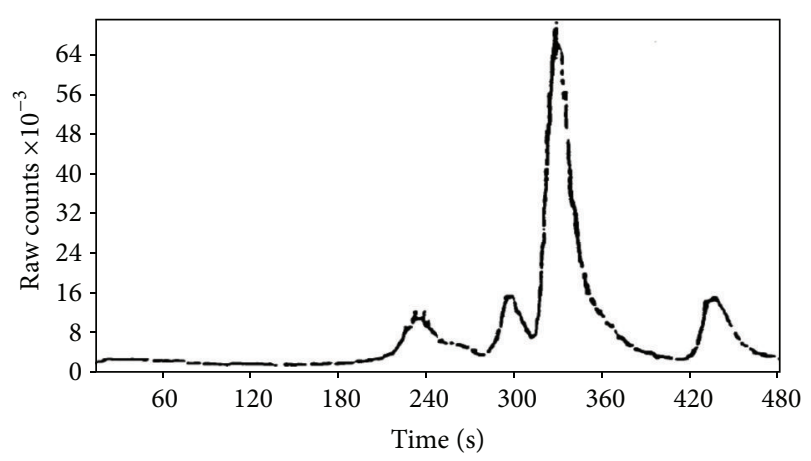

FIGURE 10: HPLC-ICPMS chromatogram obtained for CF sample. experiments in which the degradation of arsenic compounds naturally presents in the brown alga Ecklonia radiata were followed when packed into 12 tubes open to air at one end only and allowed to naturally decompose under moist conditions, sections without direct contact with air when analyzed for arsenic species by HPLC/ICPMS following an aqueous methanol extraction, revealed decomposition intermediate products consisting of dimethylarsinoylethanol, DMAE and dimethylarsinic acid, DMAA [16].

The HPLC-ICPMS chromatogram of the control methanol soluble filtrate sample CF revealed four arsenic peaks whose retention times: 194-275 s, 275-306 s, 306-370 s, and 415-470 s matched the retention times for the mixture of DMAE and DMAA, AS2, AS1 (major), and an unknown hidden arsenic species, respectively. In the timed degradation experiment involving Ecklonia radiata as well, it was observed that the section with direct contact with air degraded more slowly and significant amounts of arsenosugars remained after 25 days [16]. Unlike the main filtrate sample SF which revealed only a mixture of DMAE and DMAA, we have identified five organoarsenic species, DMAA, DMAE, AS1, AS2, and one unknown hidden arsenic species in the control filtrate sample. This confirms the importance of microbial activity, peculiar only to marine sediment necessary for the complete conversion of hidden organoarsenic species to either or both DMAE and DMAA $[14,15,19,22]$. In addition, this result supports previous findings which suggested that a microbially mediated stage, probably occurring within sediments, is necessary for the generation of arsenobetaine from arsenoribosides $[14,15,19,28]$.

\section{Conclusions}

The identification of DMAE and DMAA in the anaerobic decomposition products of Fucus distichus incubated in a closed system confirms these compounds as degradation products of the organoarsenic compounds present in this seaweed. AS1 and AS2 that were identified in the decomposition mixtures of the Fucus distichus suggested that these arsenoribosides were the hidden organoarsenic species that were being biotransformed, in part by the microbial activity in the sediment mixed with the seawater. The equilibrium decomposition mixtures of the control filtrate extract was characterized with five arsenic species, three hidden organoarsenic species, AS1 and AS2, and an unidentified organoarsenic species, in addition to the two decomposition products of DMAE and DMAA. The closed anaerobic decomposition procedure, therefore, has allowed for the characterization of all possible metabolites occurring during the anaerobic decomposition process based on these results. In addition, the results support the view that microbial activity, peculiar to the beach sediment, is necessary for completing biotransformation of the organoarsenic compounds present in the marine organism. Furthermore, the identification of both DMAE and DMAA as biotransformation products of the closed anaerobic decomposition experiment suggests strongly that they are strong intermediate candidates for the generation of arsenobetaine, from arsenoribosides in the marine food webs. 


\section{Acknowledgments}

The authors appreciate the financial support provided by the Natural Sciences and Engineering Research Council of Canada. The analytical support of Dr. Xiao Chun Lee for the HPLC-ICPMS was appreciated.

\section{References}

[1] D. Fattorini, C. M. Alonso-Hernandez, M. Diaz-Asencio et al., "Chemical speciation of arsenic in different marine organisms: importance in monitoring studies," Marine Environmental Research, vol. 58, no. 2-5, pp. 845-850, 2004.

[2] M. A. Rahman, H. Hasegawa, and R. P. Lim, "Bioaccumulation, biotransformation and trophic transfer of arsenic in the aquatic food chain," Environmental Research, vol. 116, pp. 118-135, 2012.

[3] W. R. Cullen and K. J. Reimer, "Arsenic speciation in the environment," Chemical Reviews, vol. 89, no. 4, pp. 713-764, 1989.

[4] K. A. Francesconi, "Arsenic species in seafood: origin and human health implications," Pure and Applied Chemistry, vol. 82, no. 2, pp. 373-381, 2010.

[5] V. F. Taylor, B. P. Jackson, M. R. Siegfried et al., "Arsenic speciation in food chains from mid-Atlantic hydrothermal vents," Environmental Chemistry, vol. 9, no. 2, pp. 130-138, 2012.

[6] J. G. Sanders, "The concentration and speciation of arsenic in marine macro-algae," Estuarine and Coastal Marine Science, vol. 9, no. 1, pp. 95-99, 1979.

[7] Y. Nakajima, Y. Endo, Y. Inoue et al., "Ingestion of Hijiki seaweed and risk of arsenic poisoning," Applied Organometallic Chemistry, vol. 20, no. 9, pp. 557-564, 2006.

[8] S. Miyashita, M. Shimoya, Y. Kamidate et al., "Rapid determination of arsenic species in freshwater organisms from the arsenic-rich Hayakawa River in Japan using HPLC-ICP-MS," Chemosphere, vol. 75, no. 8, pp. 1065-1073, 2009.

[9] Y. Shibata and M. Morita, "Characterization of organic arsenic compounds in bivalves," Applied Organometallic Chemistry, vol. 6, pp. 343-349, 1992.

[10] S. Tamaki and W. T. Frankenberger Jr., "Environmental biochemistry of arsenic," Reviews of Environmental Contamination and Toxicology, vol. 124, pp. 79-110, 1992.

[11] V. Nischwitz and S. A. Pergantis, "First report on the detection and quantification of arsenobetaine in extracts of marine algae using HPLC-ES-MS/MS," Analyst, vol. 130, no. 10, pp. 13481350, 2005.

[12] M. Grotti, F. Soggia, C. Lagomarsino, W. Goessler, and K. A. Francesconi, "Arsenobetaine is a significant arsenical constituent of the red Antarctic alga Phyllophora antarctica," Environmental Chemistry, vol. 5, no. 3, pp. 171-175, 2008.

[13] J. S. Edmonds and K. A. Francesconi, "Organoarsenic compounds in the marine environment," in Organometallic Compounds in the Environment, P. J. Craig, Ed., pp. 195-222, John Wiley \& Sons, New York, NY, USA, 2003.

[14] J. S. Edmonds and K. A. Francesconi, "Arseno-sugars from brown kelp (Ecklonia radiata) as intermediates in cycling of arsenic in a marine ecosystem," Nature, vol. 289, no. 5798, pp. 602-604, 1981.

[15] J. S. Edmonds, K. A. Francesconi, and J. A. Hansen, "Dimethyloxarsylethanol from anaerobic decomposition of brown kelp (Ecklonia radiata): a likely precursor of arsenobetaine in marine fauna," Experientia, vol. 38, no. 6, pp. 643-644, 1982.
[16] J. Navratilova, G. Raber, S. J. Fisher, and K. A. Francesconi, "Arsenic cycling in marine systems: degradation of arsenosugars to arsenate in decomposing algae, and preliminary evidence for the formation of recalcitrant arsenic," Environmental Chemistry, vol. 8, no. 1, pp. 44-51, 2011.

[17] J. S. Edmonds and K. A. Francesconi, "Transformations of arsenic in the marine environment," Experientia, vol. 43, no. 5, pp. 553-557, 1987.

[18] J. S. Edmonds and K. A. Francesconi, "The origin of arsenobetaine in marine animals," Applied Organometallic Chemistry, vol. 2, pp. 297-302, 1988.

[19] A. W. Ritchie, J. S. Edmonds, W. Goessler, and R. O. Jenkins, "An origin for arsenobetaine involving bacterial formation of an arsenic-carbon bond," FEMS Microbiology Letters, vol. 235, no. 1, pp. 95-99, 2004.

[20] D. J. H. Phillips and M. H. Depledge, "Metabolic pathways involving arsenic in marine organisms: a unifying hypothesis," Marine Environmental Research, vol. 17, no. 1, pp. 1-12, 1985.

[21] A. D. Welch and R. L. Landau, "The arsenic analog of cholines as a component of lecithin in rats fed arsenocholine chloride," The Journal of Biological Chemistry, vol. 144, pp. 581-588, 1942.

[22] J. Kirby, W. Maher, and D. Spooner, "Arsenic occurrence and species in near-shore macroalgae-feeding marine animals," Environmental Science and Technology, vol. 39, no. 16, pp. 59996005, 2005.

[23] K. J. Reimer, "The methylation of arsenic in marine sediments," Applied Organometallic Chemistry, vol. 3, pp. 475-490, 1989.

[24] C. F. Harrington, A. A. Ojo, V. W.-M. Lai, K. J. Reimer, and W. R. Cullen, "The identification of some water-soluble arsenic species in the marine brown algae Fucus distichus," Applied Organometallic Chemistry, vol. 11, no. 12, pp. 931-940, 1997.

[25] J. Feldmann, S. Devalla, A. Raab, and H. R. Hansen, "Analytical strategies for arsenic speciation in environmental and biological samples," in Organic Metal and Metalloid Species in the Environment Analysis, Distribution, Processes and Toxicological Evaluation, A. V. Hirner and H. Emons, Eds., vol. 18, pp. 41-70, Springer, Berlin, Germany, 2004.

[26] U. Bose, M. Rahman, and M. Alamgir, "Arsenic toxicity and speciation analysis in ground water samples: a review of some techniques," International Journal of Chemical Technology, vol. 3, pp. 14-25, 2011.

[27] K. A. Francesconi, "Current perspectives in arsenic environmental and biological research," Environmental Chemistry, vol. 2, no. 3, pp. 141-145, 2005.

[28] A. Price, W. Maher, J. Kirby et al., "Distribution of arsenic species in an open seagrass ecosystem: relationship to trophic groups, habitats and feeding zones," Environmental Chemistry, vol. 9, no. 1, pp. 77-88, 2012. 

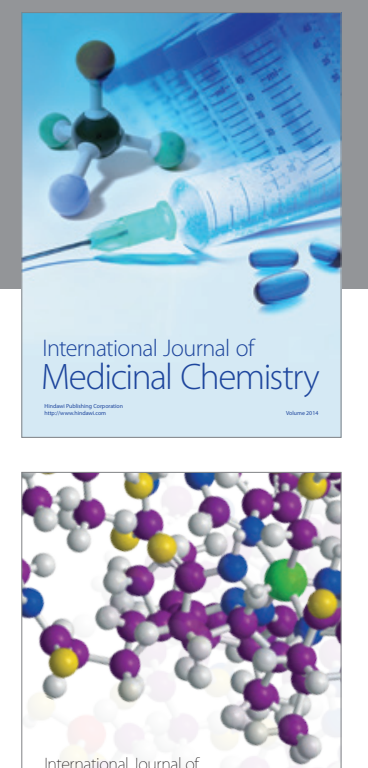

\section{Carbohydrate} Chemistry

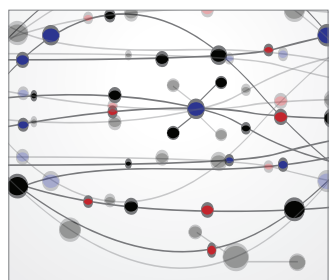

The Scientific World Journal
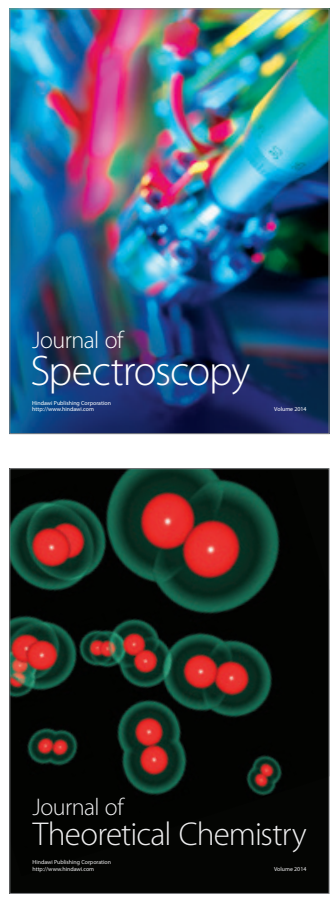
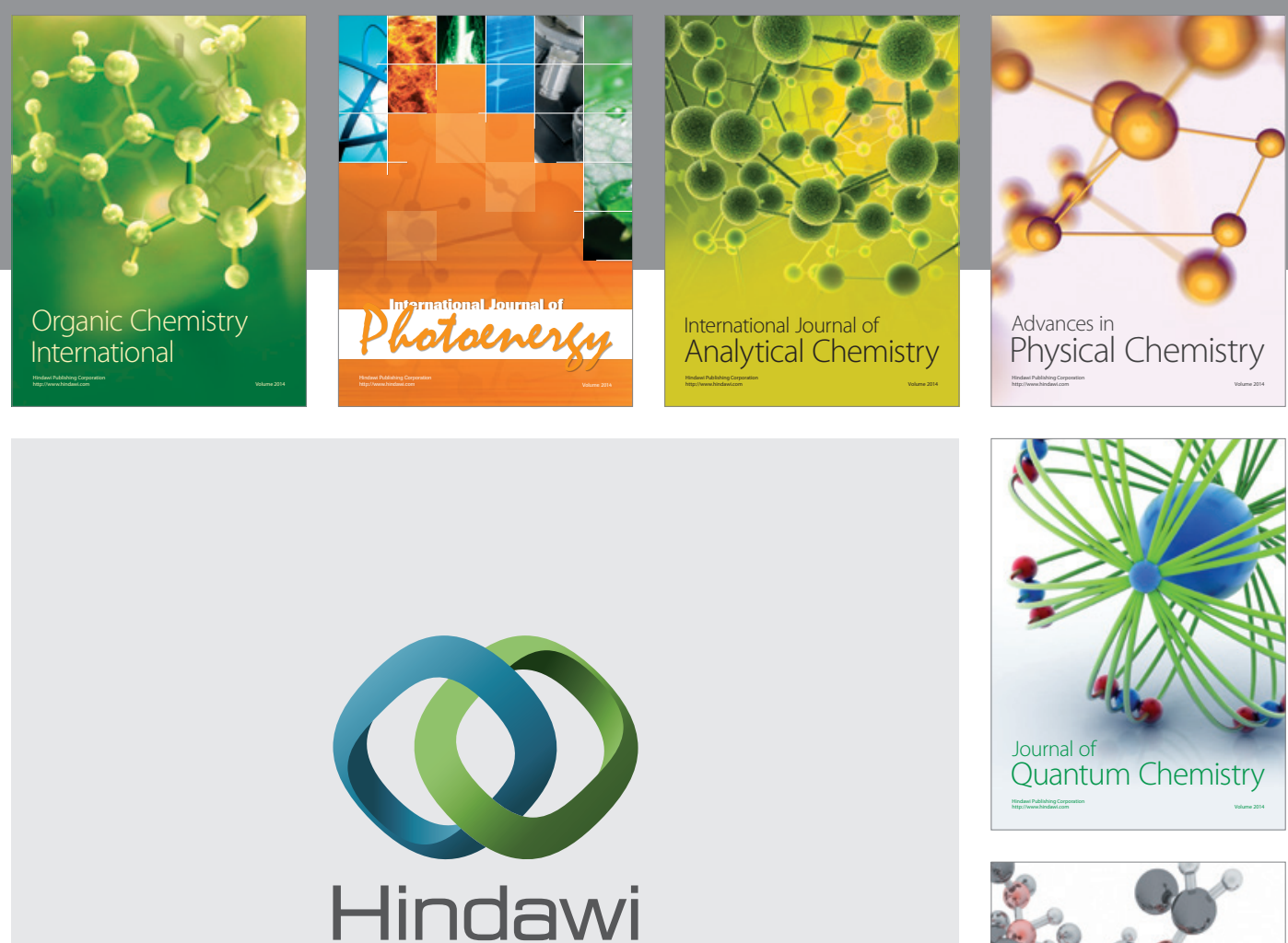

Submit your manuscripts at

http://www.hindawi.com

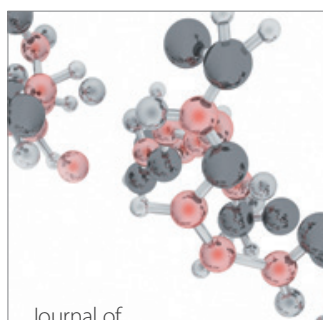

Analytical Methods

in Chemistry

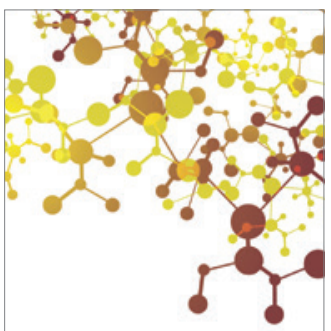

Journal of

Applied Chemistry

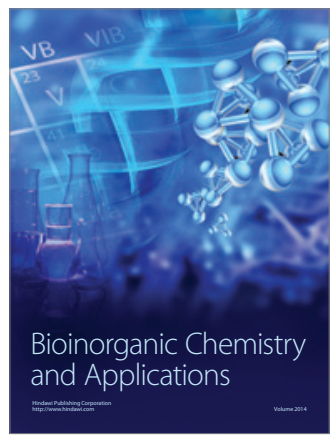

Inorganic Chemistry
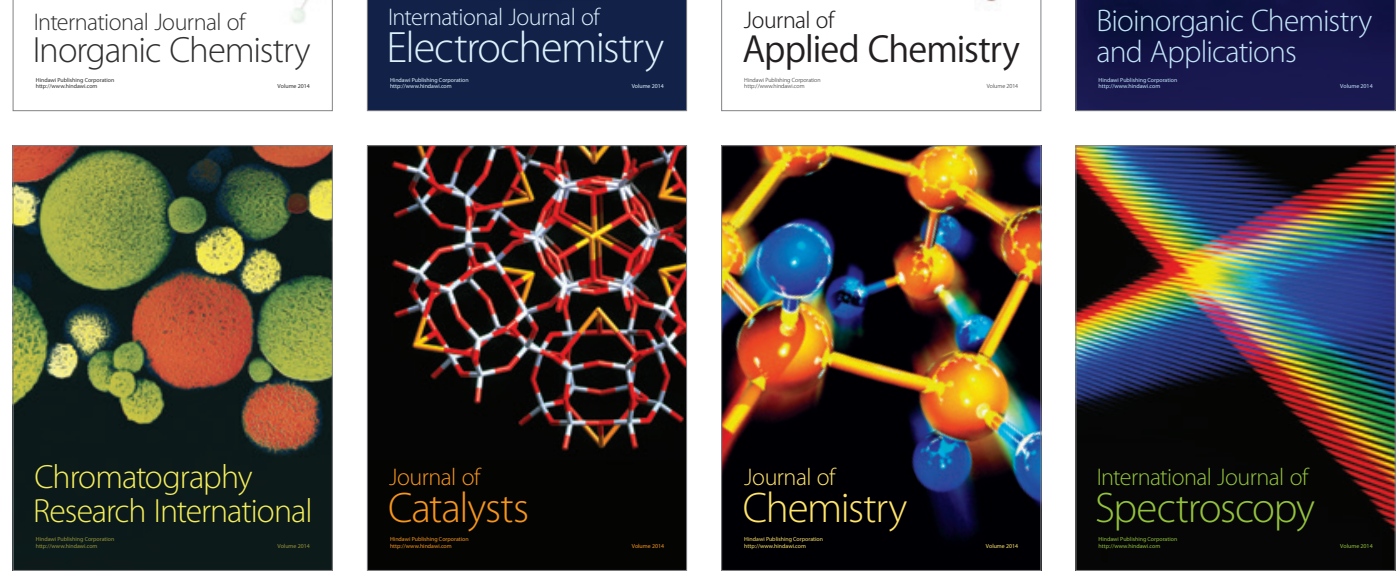